\title{
One year period prevalence study of respiratory acidosis in acute exacerbations of COPD: implications for the provision of non-invasive ventilation and oxygen administration
}

\author{
P K Plant, J L Owen, M W Elliott
}

\begin{abstract}
Background-Non-invasive ventilation (NIV) reduces mortality and intubation rates in patients with chronic obstructive pulmonary disease (COPD) admitted to hospital with respiratory acidosis. This study aimed to determine the prevalence of respiratory acidosis in patients admitted with COPD, to draw inferences about oxygen therapy, and to determine the need for NIV services for acute COPD in
\end{abstract} typical UK hospitals.

Methods-This one year prospective prevalence study identified patients with COPD aged 45-79 years inclusive who were admitted to Leeds General Infirmary, St James's University, and Killingbeck Hospitals, Leeds between 1 March 1997 and 28 February 1998. The prevalence of respiratory acidosis and the relationship with oxygenation are described. Other outcomes included intensive care use and in hospital mortality. From this data population prevalence estimates were determined for respiratory acidosis, from which the need for NIV in a typical district general hospital was modelled.

Results-983 patients were admitted, 11 of whom required immediate intubation. $20 \%$ of the remaining 972 had a respiratory acidosis. Acidosis was associated with subsequent admission to the intensive care unit (ICU): $\mathrm{pH}<7.25$, OR $6.10(95 \%$ confidence interval (CI) 1.19 to 31.11$) ; \mathbf{p H}$ 7.25-7.30, OR 8.73 (95\% CI 2.11 to 36.06$)$. pH was inversely correlated with arterial oxygen tension $\left(\mathrm{PaO}_{2}\right)$ in the $47 \%$ of patients who were hypercapnic, with a $\mathrm{PaO}_{2}$ of $>10 \mathrm{kPa}$ being associated with acidosis in most hypercapnic patients. $80 \%$ remained acidotic after initial treatment, giving an age/sex specific prevalence for England and Wales of 75 (95\% CI 61 to 90)/ 100 000/year for men aged 45-79 years and $57(95 \%$ CI 46 to 69)/100 000/year for women. Modelling the need for NIV for all COPD patients indicates that a typical UK hospital will admit 90 patients per year with acidosis of which 72 will require NIV. Conclusions-In patients with acute COPD the $\mathrm{PaO}_{2}$ should be maintained at $7.3-10 \mathrm{kPa}\left(\mathrm{SaO}_{2}, 85-92 \%\right)$ to avoid the dangers of hypoxia and acidosis. If all COPD patients with a respiratory acidosis $(\mathrm{pH}<7.35)$ after initial treatment are of- fered NIV, a typical UK hospital will treat 72 patients per year.

(Thorax 2000;55:550-554)

Keywords: respiratory insufficiency; chronic obstructive pulmonary disease; non-invasive ventilation

Chronic obstructive pulmonary disease (COPD) is a major cause of hospital admission in the UK. Department of Health figures suggest that a typical UK district general hospital (DGH) serving a population of 250000 will admit 680 patients per year. ${ }^{1}$ A proportion of patients with more severe disease will have a respiratory acidosis $\left(\mathrm{pH}<7.35\right.$ and $\mathrm{PaCO}_{2}$ $>6 \mathrm{kPa}$ ) as a result of acute on chronic respiratory failure. Acidosis is associated with increased mortality and also a higher need for intubation. ${ }^{23}$ Non-invasive ventilation (NIV) using a face or nasal mask has been shown in randomised controlled trials to reduce the need for subsequent intubation and mortality in this group of patients. ${ }^{4-6}$ Two cohort studies have also reported a long term survival advantage. ${ }^{78}$ In 1997 Baldwin and Allen recommended that all patients with COPD with a respiratory acidosis $(\mathrm{pH}<7.35)$ should receive NIV, ${ }^{9}$ and the British Thoracic Society published guidelines which recommended that NIV should be given to those with a pH of $<7.25$ and should be considered for those with a $\mathrm{pH}$ between 7.25 and $7.35 .{ }^{10}$ However, it is difficult to implement this recommendation without knowing the need for NIV - that is, the prevalence of respiratory acidosis. This study aimed to provide this information and to make recommendations on service provision.

\section{Methods}

A one year prospective period prevalence study was conducted in Leeds (population 727 000) ${ }^{11}$ between 1 March 1997 and 28 February 1998 following a one month pilot study. Patients aged 45-79 years inclusive, admitted to St James's University Hospital, Leeds General Infirmary, and Killingbeck Hospital with a respiratory diagnosis or symptoms were identified from the admission offices daily by one of two researchers. The notes were reviewed to identify patients with an acute exacerbation of COPD. Inclusion criteria were admission diagnosis of COPD/asthma (or associated synonyms) and age 45-79 years inclusive. Exclusion criteria were symptoms prior to age 45 years, no history of tobacco use, 
and asthma previously diagnosed by a consultant chest physician. Inter-rater reliability was assessed independently over a three day period by both observers performing the survey. The kappa statistic was used to assess inter-rater reliability for both steps of the process - that is, note identification from the admission records and inclusion in the study after review of the medical notes. Age, sex, date of admission, and the first arterial blood gas tension were recorded (either in the accident and emergency (A\&E) department or ward). Normalisation of $\mathrm{pH}$ to the range $7.35-7.45$ between the $\mathrm{A} \& \mathrm{E}$ department and the ward was recorded. $\mathrm{FiO}_{2}$ could not be reliably recorded because it was not always documented in the medical notes. The date of discharge, intensive care (ICU), use and in hospital mortality were obtained retrospectively from the hospital patient administration system and the ICU computer databases in combination with note retrieval. Hospital coding data for COPD (ICD codes 490-496) in the first three diagnoses coded were obtained for $1995 / 6,1996 / 7$, and $1997 / 8$ to determine whether the year under study was typical. Prevalence data were calculated and modelled using population data (ICD codes 490-496). ${ }^{11-13}$

\section{STATISTICAL ANALYSIS}

Data were analysed using Access 97 and SPSS (version 8). Percentages are reported with 95\% confidence intervals $(95 \% \mathrm{CI})$, means \pm standard deviations (SD) and medians with fifth and 95th centiles. All tests and $\mathrm{p}$ values are two tailed. Pearson's correlation coefficient was used to assess associations between blood gas variables and forward stepwise logistic regression to identify variables associated with subsequent ICU use and mortality. Odds ratios (OR) are reported with 95\% CIs. Medians were compared using the Mann-Whitney U test.

\section{Results}

ADMISSION DATA

Between 1 March 1997 and 28 February 1998 983 patient admissions met the inclusion and exclusion criteria (table 1). Twenty two patients were admitted to the ICU with an acute exacerbation of COPD, 12 from the A\&E department (11 intubated pre-ICU) and 10 from the ward. The outcomes are shown in table 1. The 11 intubated in the $A \& E$ department have been excluded from further analysis as immediate need for intubation was an exclusion criterion in the randomised controlled trials of NIV. ${ }^{4-6}$ Inter-rater reliability was high for note retrieval $(\kappa=0.98)$ and diagnosis $(\kappa=1.0)$. An arterial blood gas tension was recorded in $94.6 \%$ of patients (918/972); 454 patients $(46.7 \%, 95 \%$ CI 43.6 to 49.8$)$ were hypercapnic and $199(20.4 \%, 95 \%$ CI 17.9 to 22.9$)$ had a respiratory acidosis $(\mathrm{pH}$ $<7.25$ ( $\mathrm{n}=45), 4.6 \%$ (95\% CI 3.3 to 5.9$) ; \mathrm{pH}$ $7.25-<7.30(\mathrm{n}=47), 4.8 \%(95 \%$ CI 3.3 to 5.9); $\mathrm{pH} 7.30-7.35(\mathrm{n}=107), 9.0 \%(95 \%$ CI 7 to 11$)$ ). Forty of the 199 patients $(20.1 \%(95 \%$ CI 14.5 to 25.7$)$ ) normalised their $\mathrm{pH}$ on arrival in the ward, leaving 159 patients $(16.4 \%$
Table 1 Characteristics and outcomes of study population

\begin{tabular}{|c|c|}
\hline Mean (SD) age (years) & $67.5(7.38)$ \\
\hline$M: F$ ratio & $492: 480$ \\
\hline \multicolumn{2}{|c|}{$\begin{array}{l}\text { Arterial gas tension on admission (median, } 5 \text { th and 95th } \\
\text { centiles) }\end{array}$} \\
\hline $\mathrm{pH}$ & $7.410(7.25,7.506)$ \\
\hline $\mathrm{PaCO}_{2}$ & $5.96(4.00,10.19)$ \\
\hline $\mathrm{PaO}_{2}$ & $9.10(5.30,18.21)$ \\
\hline \multicolumn{2}{|l|}{ ICU use and outcomes } \\
\hline \multicolumn{2}{|l|}{ ICU use } \\
\hline Including $\mathrm{A} \& \mathrm{E}$ intubations & $\begin{array}{l}22 / 983(2.2 \%, 95 \% \text { CI } 1.3 \\
\quad \text { to } 3.2)\end{array}$ \\
\hline Excluding $\mathrm{A} \& \mathrm{E}$ intubations & $\begin{array}{l}11 / 972(1.1 \%, 95 \% \text { CI } 0.5 \\
\text { to } 1.8)\end{array}$ \\
\hline \multicolumn{2}{|l|}{ Mortality of ICU users } \\
\hline Including $\mathrm{A} \& \mathrm{E}$ intubations & $\begin{array}{l}\text { 4/11 died in ICU, } 5 / 11 \\
\text { died during admission }\end{array}$ \\
\hline Excluding $\mathrm{A} \& \mathrm{E}$ intubations & $\begin{array}{l}2 / 11 \text { dies in ICU, } 5 / 11 \text { died } \\
\text { during admission }\end{array}$ \\
\hline $\begin{array}{l}\text { Median length of stay in ICU } \\
\text { (days) }\end{array}$ & 1 (range $0-4$ ) \\
\hline \multicolumn{2}{|l|}{ Outcomes } \\
\hline \multicolumn{2}{|l|}{ In hospital mortality } \\
\hline Whole group & $\begin{array}{l}77 / 972(7.9 \%, 95 \% \text { CI } 6.2 \\
\text { to } 9.6)\end{array}$ \\
\hline Non-acidotic subgroup & $\begin{array}{l}53 / 773(6.9 \%, 95 \% \text { CI } 5.1 \\
\text { to } 8.6)\end{array}$ \\
\hline Acidotic subgroup & $\begin{array}{l}24 / 199(12.1 \%, 95 \% \mathrm{CI} \\
\quad 7.5 \text { to } 16.6)\end{array}$ \\
\hline $\begin{array}{l}\text { Persistently acidotic } \\
\text { subgroup }\end{array}$ & $\begin{array}{l}22 / 159(13.8 \%, 95 \% \mathrm{CI} \\
\quad 8.5 \text { to } 19.2)\end{array}$ \\
\hline $\begin{array}{l}\text { Median length of stay ( } 5 \text { th, } \\
\text { 95th centiles) }\end{array}$ & $\begin{array}{l}8 \text { days }(2,35 \text { days, range } \\
0-95)\end{array}$ \\
\hline
\end{tabular}

(95\% CI 14.1 to 18.7 ) who met criteria for NIV. One hundred and twenty two patients accounted for the 199 acidotic admissions; 25 were admitted with acidosis on more than one occasion $(20 \%)$ in the study period.

Acidosis on admission was the only variable on multivariate analysis which was associated with subsequent ICU use. Compared with the group without acidosis, the OR for intubation for patients with a $\mathrm{pH}$ of $<7.25$ was $6.10(95 \%$ CI 1.19 to $31.11, \mathrm{p}=0.01)$ and $8.73(95 \% \mathrm{CI}$ 2.11 to $36.06, \mathrm{p}<0.01$ ) for the group with a $\mathrm{pH}$ of 7.25-7.30. Increasing age alone was associated with increased mortality (OR 1.07 per year ( $95 \%$ CI 1.03 to 1.11$), \mathrm{p}<0.01)$. There was no association between acidosis and mortality.

VARIABILITY IN ADMISSION RATES WITHIN AND BETWEEN YEARS

Figure 1 shows the COPD admissions by month. Total admission rates fall in the summer but the rate of respiratory acidosis was more constant at 18 per month (range 9-22). The year was typical for COPD admissions; 1577 consultant episodes were coded in $1995 / 6,1514$ in $1996 / 7$, and 1601 in $1997 / 8$.

\section{ASSOCIATION WITH OXYGENATION}

For hypercapnic patients a higher $\mathrm{PaO}_{2}$ was associated with worse acidosis $(r=-0.214$, $\mathrm{p}<0.01)$. Most of the hypercapnic patients with a $\mathrm{PaO}_{2}$ of $>10 \mathrm{kPa}$ were acidotic. Figure 2 is a box and whisker plot which shows the distribution of $\mathrm{pH}$ by four arbitrary but clinically meaningful oxygen categories: group $1, \mathrm{PaO}_{2}$ $<7.3 \mathrm{kPa}$ (that is, long term oxygen threshold); group 2, 7.3-<10 kPa; group 3, $10-13.3 \mathrm{kPa}$ (that is, normal range); and group $4,>13.3 \mathrm{kPa}$. The only variable that was significantly different 


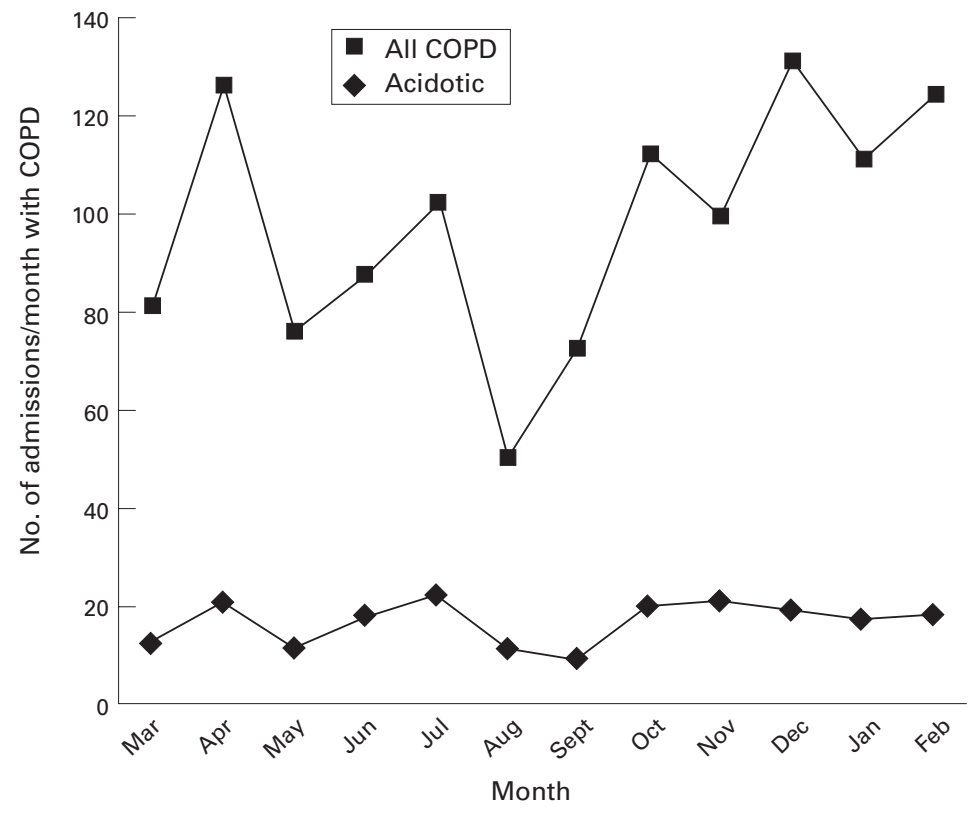

Figure 1 Admissions per month with COPD.

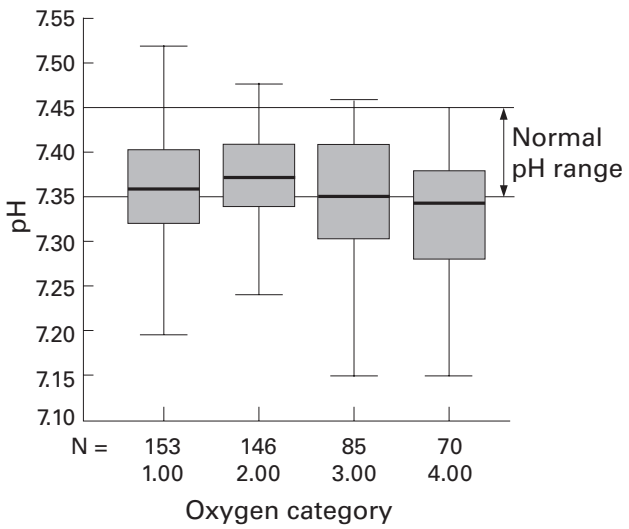

Figure 2 Box and whisker plot of $p H$ for all hypercapnic patients by $\mathrm{PaO}_{2}$ group (see text).

between acidotic patients who normalised their $\mathrm{pH}$ and those who did not was the initial $\mathrm{PaO}_{2}$ (median $\mathrm{PaO}_{2} 10.30 \mathrm{kPa}$ versus $8.49 \mathrm{kPa}, \mathrm{p}=$ $0.01)$. In most instances it was observed that $\mathrm{FiO}_{2}$ had been reduced between the $\mathrm{A} \& \mathrm{E}$ department and the ward. Table 2 shows that correction of acidosis was not related to its initial severity in this group. No variable was sufficiently predictive to reliably differentiate those who did and did not normalise their $\mathrm{pH}$.

\section{MODELLING OF WORKLOAD AND IMPLICATIONS}

FOR LOCATION OF ACUTE NIV SERVICE

The age (45-79 years) and sex specific rates for acidosis in Leeds are 93/100 000/year (95\% CI 76 to 111 ) for men and 70/100 000/year (95\% CI 56 to 85) for women. However, these data are not generalisable to UK practice as Leeds and West Yorkshire has a higher prevalence of

Table 2 Median pH of acidotic patients by oxygen category with \% fully correcting the pH on arrival to the ward

\begin{tabular}{lllll}
\hline & $<7.3 \mathrm{kPa}$ & $7.3-10.0 \mathrm{kPa}$ & $10-13.3 \mathrm{kPa}$ & $>13.3 \mathrm{kPa}$ \\
\hline $\begin{array}{l}\text { Median } \mathrm{pH} \\
\text { \% Improved }\end{array}$ & 7.319 & 7.313 & 7.303 & 7.290 \\
\hline
\end{tabular}

COPD based on standardised mortality ratios (men 124, women 123). ${ }^{12}$ Standardised rates for England and Wales are 75/100 000/year (95\% CI 61 to 90 ) for men and 57/100 000/ year (95\% CI 46 to 69 ) for women. The analysis omits the very elderly (over 80 years). It is possible to model this workload on the assumption that treatment in the very elderly is appropriate, that the proportion of COPD patients admitted with acidosis is the same as in the 45-79 year group, and that mortality statistics can be used as a marker of disease prevalence. On the basis of our data and these assumptions, a typical DGH (population 250000 , standardised mortality ratio 100) will admit 90 patients per year, of whom 72 will require NIV ( 38 men and 34 women), equating to six per month (two $\mathrm{pH}<7.25$, two $7.25-7.30$, and two 7.30-7.35). It is possible to model the impact of service structure on monthly NIV rates using the Poisson distribution. ${ }^{14}$ If all six patients are managed in one location, the percentage of months in which one or fewer patients are treated is $1.7 \%$ compared with $20 \%$ if two locations are used.

\section{Discussion}

During a 12 month period 983 patients were admitted with an acute exacerbation of COPD, confirming that this is a very common reason for hospital admission. Twenty percent were acidotic; acidosis in acute exacerbations of COPD is predictive of subsequent ICU use and mortality. ${ }^{2-4}$ The relationship with ICU use was confirmed in this study, but no relationship was seen with mortality; this may reflect the confounding effect of NIV provision in the hospitals studied. In $20 \%$ of the acidotic patients $\mathrm{pH}$ normalised between the $\mathrm{A} \& \mathrm{E}$ department and the ward without assisted ventilation.

\section{OXYGEN THERAPY}

The $20 \%$ who normalised their $\mathrm{pH}$ could not be reliably predicted, but the data suggest that a proportion had been made acidotic by injudicious oxygen therapy and were able to rapidly correct their $\mathrm{pH}$ once $\mathrm{FiO}_{2}$ was reduced. For hypercapnic patients, who made up $47 \%$ of the admissions, there was an inverse correlation between $\mathrm{pH}$ and $\mathrm{PaO}_{2}$ with more than $50 \%$ of patients with a $\mathrm{PaO}_{2}$ of $>10 \mathrm{kPa}$ being acidotic.

The main limitation of these data is that we can only show an association between acidosis and oxygen therapy rather than a causative relationship, as patients received oxygen in ambulances and on arrival at the A\&E department before blood gas analysis. However, it is difficult to see how recommendations can be grounded on experimental studies as these would need to recruit emergency patients before oxygen administration in ambulances. Studies on patients with stable COPD may not be applicable to unstable patients. A further limitation is that we were not always able to determine the $\mathrm{FiO}_{2}$ from the medical notes because of poor record keeping. However, recommending a range of $\mathrm{PaO}_{2}$ and its associated $\mathrm{SaO}_{2}$ rather than a predetermined $\mathrm{FiO}_{2}$ allows tailoring of oxygen therapy to an individual 
patient. The data support the view that $\mathrm{PaO}_{2}$ should be maintained below $10 \mathrm{kPa}$ with controlled oxygen to avoid the risk of acidosis. This observation may explain the very high intubation rate in the study described by Brochard et al in which $\mathrm{SaO}_{2}$ was maintained at over $92 \% .^{5}$ However, to impact on current practice it will also be necessary to provide a lower limit of acceptable $\mathrm{PaO}_{2}$. There is some suggestion from the data that acidosis is minimised in the $\mathrm{PaO}_{2}$ range $7.3-10 \mathrm{kPa}$. A lower limit of $\mathrm{PaO}_{2}$ of $7.3 \mathrm{kPa}$ also provides consistency with the current recommendations for long term oxygen therapy. ${ }^{9}$ This range of $\mathrm{PaO}_{2}$ $(7.3-10 \mathrm{kPa})$ equates to an $\mathrm{SaO}_{2}$ of $85-92 \%$. This approach has been shown to be effective in titrating oxygen during mechanical ventilation. ${ }^{15}$ For pre-hospital care this would require oximeters to be provided in ambulances. Future work may compare the current approach to oxygen therapy with tailored oxygen to the above $\mathrm{SaO}_{2}$ in ambulances and the $\mathrm{A} \& \mathrm{E}$ department.

IMPLICATIONS FOR NIV PROVISION

For a DGH in the UK serving a population of 250000,90 patients will be admitted with acidosis each year of whom 72 will require NIV. This workload is less variable over the year than total COPD admissions and equates to six patients per month (three men and three women), four of whom will have a $\mathrm{pH}$ of $<7.30$.

The lack of seasonality in the NIV workload is surprising but, using hospital coding data, the year under study appears typical. Coding statistics overestimate the true admission rate as they include individual consultant episodes and the first three discharge diagnoses, whether these be the cause of the admission or not. In winters associated with influenza epidemics the demand for NIV is likely to be higher.

The main limitation of the method used to derive these estimates is that we only identified those who were acidotic on admission and would not have detected those who deteriorated later, thereby underestimating the need for NIV. This is an intrinsic flaw in the study design, but the number of patients in this category is likely to be low. Of the 21 ICU patients who were intubated, 18 were intubated within 24 hours of admission; two of the remaining three were intubated more than two weeks after admission. This indicates that most patients who are admitted with an exacerbation of COPD who deteriorate do so very early in the admission. This observation is supported by data from the control arms of the randomised controlled trials. Wood et $a l^{16}$ found that the median time to intubation was 4.8 hours from admission. Similarly, Brochard et $a \bar{l}$ found that $73 \%$ of the 31 patients who subsequently required intubation were intubated within the first 12 hours. A second limitation of this study is that not all patients who were acidotic in the $\mathrm{A} \& \mathrm{E}$ department had gas tension measurements repeated on arrival at the ward. This could lead to an overestimate of the need for NIV.

These estimates have significance for service provision and planning, since COPD is likely to be the major indication for acute NIV in most hospitals. Several factors need considering in planning acute NIV services-namely, the availability of intubation for those who deteriorate, the location of the service, the expected throughput, and its effect on skill retention. The availability of intubation is important if the trend to increased mortality with NIV demonstrated by Wood et $a l^{16}$ is to be avoided. Concerning location, the routine use of NIV in the A\&E department cannot be advocated at present as the two randomised controlled trials recruited in this setting failed to show any benefit. ${ }^{16}{ }^{17}$ However, both studies were small and our observation that $20 \%$ of patients correct their $\mathrm{pH}$ very rapidly with initial treatment may explain the absence of either deaths or intubations in the study by Barbe et $a l .{ }^{17}$ The location of the service within the hospital will also have an impact on the throughput. In most UK hospitals NIV is offered in the ward environment and not in high dependency units. ${ }^{18}$ Performing NIV on several general medical wards within one hospital will lead to very low throughput to an individual ward and difficulty in maintaining skills. Even if NIV is confined to two single sex wards, throughput will only be three per month and in $20 \%$ of months less than one patient will be ventilated per month per ward. If NIV is concentrated on one mixed sex ward the monthly throughput increases to six and in less than $2 \%$ of months one patient or less be ventilated; this aids skill retention. These estimates should be interpreted in the light of the local prevalence of $\mathrm{COPD}^{12}$; areas with a high prevalence will be able to maintain skills with more than one ward offering NIV.

These data therefore suggest that, in an average DGH, six patients with an acute exacerbation of COPD will require NIV each month. In order to maintain skills and maximise expertise, NIV should probably be performed in a single clinical area in most hospitals. In a proportion of patients acidosis resolves rapidly without ventilatory support and, in these, injudicious oxygen therapy is an important factor. Targeting oxygen supplementation on $\mathrm{SaO}_{2}$ or $\mathrm{PaO}_{2}$ rather than by $\mathrm{FiO}_{2}$ may reduce the incidence of oxygen induced acidosis, but this requires confirmation in future studies.

This study was funded by the Northern and Yorkshire NHS Executive.

Conflict of interest: none

1 Anderson HR, Esmail A, Hollowell J. Epidemiologically based needs assessment: lower respiratory disease. London: Department of Health, 1994

2 Jeffrey AA, Warren PM, Flenley DC. Acute hypercapnic respiratory failure in patients with chronic obstructive lung disease: risk factors and use of guidelines for management. Thorax 1992;47:34-40

3 Ambrosino N, Foglio K, Rubini F, et al. Non-invasive mechanical ventilation in acute respiratory failure due to chronic obstructive airways disease: correlates for success. Thorax 1995;50:755-7.

4 Bott J, Carroll MP, Conway JH, et al. Randomised controlled trial of nasal ventilation in acute ventilatory failure due to chronic obstructive airways disease. Lancet 1993:341: 1555-7.

5 Brochard L, Mancebo J, Wysocki M, et al. Noninvasive ventilation for acute exacerbations of chronic obstructive pultilation for acute exacerbations of chronic obstructi
monary disease. N Engl $\mathcal{M}$ Med 1995;333:817-22.

6 Kramer N, Meyer TJ, Meharg J, et al. Randomised, prospective trial of noninvasive positive pressure ventilation 
in acute respiratory failure. Am 7 Respir Crit Care Med 1995:151:1799-806.

7 Vitacca M, Clini E, Rubini F, et al. Non-invasive mechanical ventilation in severe chronic obstructive lung disease and acute respiratory failure: short- and long-term prognosis. Intensive Care Med 1996;22:94-100.

8 Confalonieri M, Parigi P, Scartabellati A, et al. Noninvasive mechanical ventilation improves the immediate and long-term outcome of COPD patients with acute respiratory failure. Eur Respir F 1996;9:422-30.

9 Baldwin DR, Allen MB. Non-invasive ventilation for acute exacerbations of chronic obstructive pulmonary disease. BMF 1997;314:163-4.

10 British Thoracic Society. BTS guidelines for the management of chronic obstructive pulmonary disease. Thorax 1997;52(Suppl 5):S19.

11 Office for National Statistics. 1996 key population and vital statistics: local and health authority areas. London, 1998.

12 Office of Population Censuses and Surveys. 1992 mortality statistics: area. London, 1995.
13 Office for National Statistics. 1996 mortality statistics: cause. London, 1998.

14 Altman DG. Theoretical distributions. In: Altman DG, ed. Practical statistics for medical research. London: Chapman \& Hall, 1991: 48-73.

15 Jubran A, Tobin MJ. Reliability of pulse oximetry in titrating supplemental oxygen therapy in ventilator dependent patients. Chest 1990; 97:1420-5.

16 Wood KA, Lewis L, Von Harz B, et al. The use of noninvasive positive pressure ventilation in the emergency departsive positive pressure ventilation
ment. Chest 1998;113:1339-46.

17 Barbe F, Togores B, Rubi M, et al. Noninvasive ventilatory support does not facilitate recovery from acute respiratory failure in chronic obstructive pulmonary disease. Eur Respir f 1996;9:1240-5.

18 Doherty MJ, Greenstone MA. Survey of non-invasive ventilation (NIPPV) in patients with acute exacerbations of chronic obstructive pulmonary disease (COPD) in the UK. Thorax 1998;53:863-6. 